\title{
Serotonergic System in the Central Nucleus of Amygdala Mediates Can- nabidiol-Induced Sleep Alteration
}

\author{
Pei-Lu Yi ${ }^{1}$, Yi-Tes Hsiao ${ }^{2}$, Chon-Haw Tsai ${ }^{3}$, Tong-Rong Jan², Chin-Yu Lu², Fang-Chia Chang*,2,3,4 \\ ${ }^{I}$ Department of Medical Technology, Jen-Teh Junior College of Medicine, Nursing and Management, Miaoli, Taiwan \\ ${ }^{2}$ Department of Veterinary Medicine, National Taiwan University, Taipei, Taiwan \\ ${ }^{3}$ Neuroscience Laboratory, Department of Neurology, China Medical University Hospital, Taichung, Taiwan \\ ${ }^{4}$ Graduate Institute of Acupuncture Science, College of Chinese Medicine, China Medical University, Taichung, Taiwan
}

\begin{abstract}
Cannabidiol (CBD) is one of the psycho-inactive constituents of marijuana, the Cannabis sativa. The pharmacological property of $\mathrm{CBD}$, especially the anxiolytic effect, is significant in the therapeutic purposes. The central nucleus of amygdala (CeA) plays a key role in the anxiety and its related behavioral responses (e.g. sleep-wake activity), and serotonin is one of the major mediators. However, the sleep-wake effect of CBD remains unclear. This study was designed to elucidate the effects of CBD on sleep-wake alteration and the involvement of serotonin in the CeA. Administrations of 5hydroxytryptamine (5-HT), 5- $\mathrm{HT}_{1 \mathrm{~A}}$ receptor partial agonist (buspirone), 5- $\mathrm{HT}_{2}$ antagonist (ritanserin), cannabinoid $\mathrm{CB}_{1}$ receptor agonist (ACEA), or $\mathrm{CB}_{1}$ antagonist (AM-251) were employed to elucidate the action of $\mathrm{CBD}$ on CeA presynaptic $\mathrm{CB}_{1}$ receptors, serotonergic activity and the subsequent sleep alteration. We found that microinjection of $\mathrm{CBD}$ into the CeA prior to the beginning of the light period dose-dependently decreased slow wave sleep (SWS) with limited effect on rapid eye movement sleep (REMS). CBD-induced SWS suppression during the light period could be mimicked by administering serotonin into the CeA. Buspirone and ritanserin dose-dependently blocked CBD-induced SWS decrease. Furthermore, administration of AM-251 exhibits similar effect as that of CBD on sleep-wake activity, and the CBD-induced SWS decrease was partially blocked by ACEA. These observations suggest that CBD acting on the CeA neurons decreases SWS during the light phase, which is at least partially mediated by the consequence of antagonizing presynaptic $\mathrm{CB}_{1}$ receptors, enhancing serotonin release from the presynaptic terminals and subsequently acting on the postsynaptic 5$\mathrm{HT}_{2}$ receptors.
\end{abstract}

Keywords: Cannabidiol, serotonin, amygdala, sleep.

\section{INTRODUCTION}

The abuse of marijuana (the Cannabis sativa preparation), which is one of the most used illicit drugs worldwide, has drawn much attention. More than 60 active compounds (cannabinoids) have been identified in cannabis [1]. $\Delta^{9}-$ tetrahydrocannabinol $\left(\Delta^{9}\right.$-THC) and cannabidiol (CBD) are two major constituents of the Cannabis sativa [2,3]. Two cannabinoid receptors, $\mathrm{CB}_{1}$ and $\mathrm{CB}_{2}$, have been identified to date. Both $\mathrm{CB}_{1}$ and $\mathrm{CB}_{2}$ receptors are coupled to the pertussis toxin-sensitive G-protein, $\mathrm{G}_{i, o}$, which inhibits adenylate cyclase and subsequently reduces the conversion of ATP to cyclic AMP (cAMP) [4]. Activation of $\mathrm{CB}_{1}$ receptor produces psychoactive effects which are similar to the phenomenon after ingestion of cannabis, whereas activation of the $\mathrm{CB}_{2}$ receptor does not cause the psychoactive effect [5]. The $\mathrm{CB}_{1}$ receptor is highly expressed in the basal ganglia, cerebellum, hippocampus and olfactory cortex, and its expression is moderate in the cerebral cortex, amygdala, septum and brain stem [6-8]. In contrast, $\mathrm{CB}_{2}$ receptor mostly expresses in the peripheral immune cells [9], modulates the

*Address correspondence to this author at the Department of Veterinary Medicine, National Taiwan University, No. 1, Sec. 4., Roosevelt Road, Taipei 106, Taiwan; Tel: +886-2-3366-3883; Fax: +886-2-2366-1475; E-mail: fchang@ntu.edu.tw release of cytokines, and is responsible for the inflammation and the regulation of the immune system [10]. $\Delta^{9}$-THC has a strong binding affinity for the central $\mathrm{CB}_{1}$ receptors and produces psychoactive properties, including anxiogenic effect [5]; whereas CBD exhibits a low binding affinity to the $\mathrm{CB}_{1}$ receptors and has a non-psychoactive property $[5,11]$. Therefore, the central nervous system (CNS) pharmacological properties of $\mathrm{CBD}$ are more predominant in the therapeutic purposes due to its non-psychoactivity [11]. The mechanisms of cannabinoids are well investigated for $\Delta^{9}$-THC $[1,4,5]$, however the mode of therapeutic effect of CBD is less established.

The effects of $\mathrm{CBD}$, including the anxiolytic action and the influence of spontaneous sleep-wake activity, have attracted our interest, since anxiety could cause sleep disturbance and the sleep perturbation further deteriorates the syndrome of anxiety. The central nucleus of amygdala (CeA) plays a key role in the sleep-wake regulation $[12,13]$, in addition to the emotional processing [14] and anxiety-related physiological and behavioral responses, such as the fearpotentiated startle [15]. Serotonin is one of the major neurotransmitters in the CeA, and the highest density of serotonergic fibers is observed in the central nucleus, paralaminar nucleus and anterior parts of the amygdaloid [16]. This observation suggests that the serotonergic system has substan- 
tial influence on the ongoing activities of the amygdaloid complex. The $\mathrm{CB}_{1}$ receptor generally locates on the axon terminals and leads to inhibit the neurotransmitter release [17]. It has been reported that $\mathrm{CB}_{1}$ receptors and 5-HT transporters are co-distributed in the amygdala, implicating that the $\mathrm{CB}_{1}$ receptor exists on the presynaptic terminals of serotonergic fibers and the activation of $\mathrm{CB}_{1}$ receptor causes a reduction of serotonin release in amygdala [18]. $\Delta^{9}$-THC has been demonstrated to increase stage 4 sleep [19] and decrease rapid eye movement (REM) sleep [20]. As for the $\mathrm{CBD}$, intraperitoneal injection of a low dose $(20 \mathrm{mg} / \mathrm{kg})$ of CBD decreases slow-wave sleep latency in the rats, and a high dose $(40 \mathrm{mg} / \mathrm{kg})$ of CBD significantly increases slow wave sleep (SWS) [21]. REM sleep is not modified by CBD [21]. However, it has been reported that intracerebroventricular (ICV) administration of CBD during the light (rest) period increases wakefulness and decreases REM sleep in the rats [22], suggesting that the sleep-wake regulation of CBD and its underlying mechanisms remain ambiguous and limited. Recently, an interesting finding indicated that CBD displays a high potency of antagonizing $\mathrm{CB}_{1}$ receptors $[23,24]$. Therefore, we designed the present study to elucidate the sleep-wake regulation of CBD when directly administered $\mathrm{CBD}$ into the CeA, to determine whether the action of $\mathrm{CBD}$ is mediated by antagonizing the presynaptic $\mathrm{CB}_{1}$ receptors on the serotonergic fibers, and to demonstrate the involvement of serotonergic system in the CeA.

\section{MATERIALS AND METHODOLOGY}

\section{Substances}

Stock solutions of serotonin and buspirone (Tocris, Bristol, UK) were dissolved in pyrogen-free saline (PFS). AM251 (Tocris) was dissolved in PFS with $0.5 \%$ dimethyl sulfoxide (DMSO). CBD and ritanserin were dissolved in $1 \%$ ethanol, and ACEA (Tocris) were dissolved in $10 \%$ ethanol. These stock solutions were stored at $-20{ }^{\circ} \mathrm{C}$ until used. The doses of the substances used in these experiments were as follows: for CBD, 0.5 and $1.0 \mu \mathrm{g}$; for buspirone, $0.5,2.0$ and $4.0 \mu \mathrm{g}$; for ritanserin, 5.0 and $10.0 \mu \mathrm{g}$; for serotonin, 3.0 and $10.0 \mu \mathrm{g}$; for ACEA, 100.0 and $300.0 \mathrm{pmol}$ (36.6 and 109.8 ng, respectively); and $100.0 \mathrm{ng}$ AM-251. The volume of total injection was $2 \mu 1$.

\section{Animals}

Male Wistar rats (250 - $300 \mathrm{~g}$; National Laboratory Animal Breeding and Research Center, Taiwan) were used in these experiments. These animals were anesthetized (ketamine/xylazine; $87 / 13 \mathrm{mg} / \mathrm{kg}$ ), and injected with analgesic (morphine) and antibiotic (penicillin G benzathine). Rats were surgically implanted with three EEG screw electrodes (on the right hemisphere of the frontal and parietal lobes and the left hemisphere of the occipital lobe) and a microinjection guide cannulae directed into the $\mathrm{CeA}$ of the left hemisphere (AP, -2.8 $\mathrm{mm}$ from bregma; ML, $4.2 \mathrm{~mm}$; DV, 7.8 $\mathrm{mm})$. The coordinates were adopted from the Paxinos and Waton rat altas [25]. Insulated leads from EEG electrodes were routed to a Teflon pedestal (Plastics One, Roanoke, VA). The Teflon pedestal was then cemented to the skull with dental acrylic (Cranioplastic cement and Cyanoacrylate gel, Plastics One, Roanoke, VA). The incision was treated topically with polysporin (polymixin B sulfate - bacitracin zinc) and the animals were allowed to recover for seven days prior to the initiation of experiments. The rats were housed separately in individual recording cages in the isolated room, in which the temperature was maintained at $23 \pm 1{ }^{\circ} \mathrm{C}$ and the light:dark rhythm was controlled in a $12: 12 \mathrm{~h}$ cycle (40 Watt $\mathrm{x} 4$ tubes illumination). Food and water were available ad libitum. All procedures performed in this study were approved by the National Taiwan University Animal Care and Use Committee.

On the second postsurgical day, rats were connected to the recording apparatus (see later) via a flexible tether. The location of the microinjection cannuae was confirmed by injecting $0.5 \%$ trypan blue dye at the end of experiment. The recording data could be included for the subsequent analyses only when the injection target has been confirmed inside the CeA in a rat (Fig. 1). Animals were habituated by daily handling and injections of PFS timed to coincide with scheduled experimental administrations.
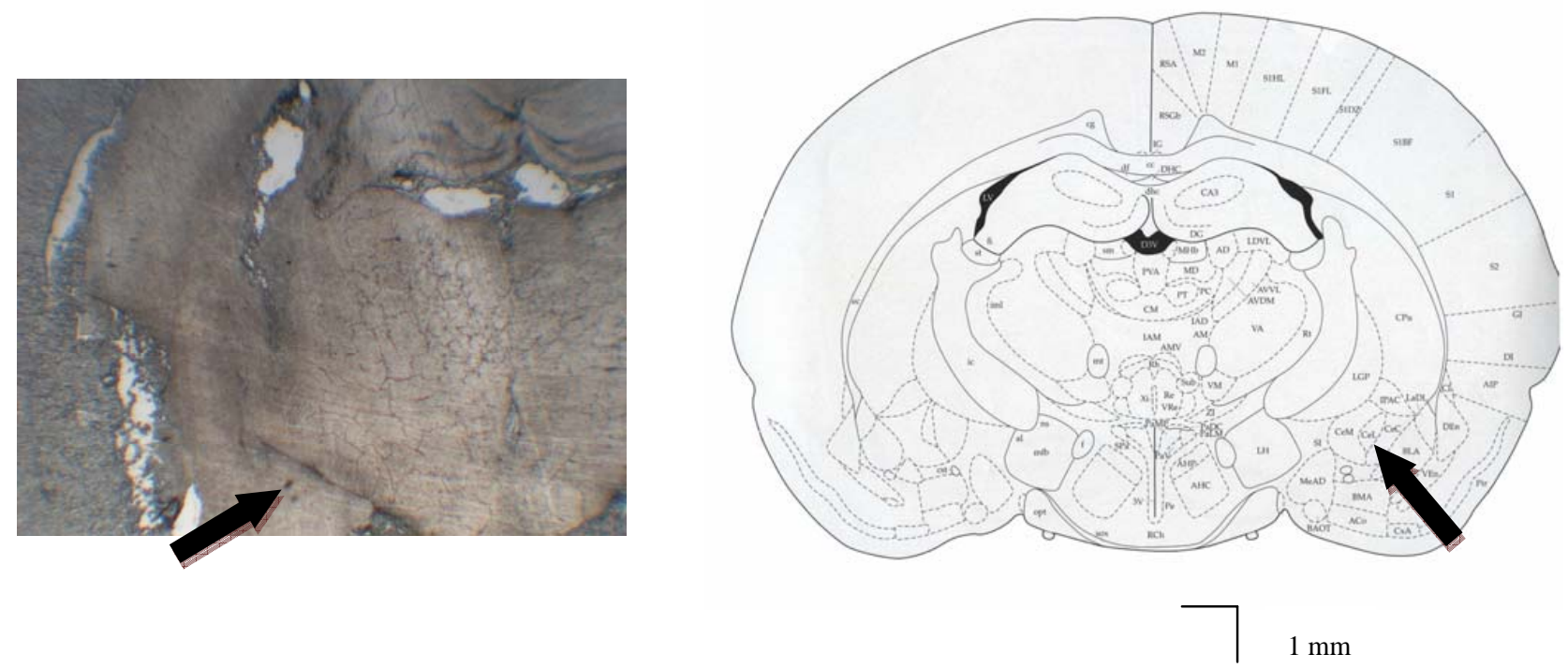

Fig. (1). The location of microinjection cannuae. Arrows point out the stain of trypan blue injected from the microinjection cannuae. 


\section{Apparatus and Recording}

Signals from the EEG electrodes were fed into an amplifier (Colbourn Instruments, Lehigh Valley, PA; model V7501 ). The EEG was amplified (factor of 5,000) and its analog bandpass filtered between 0.1 and $40 \mathrm{~Hz}$ (frequency response: $\pm 3 \mathrm{~dB}$; filter frequency roll off: $12 \mathrm{~dB} /$ octave). Gross body movements were detected by custom-made infrared-based motion detectors (Biobserve $\mathrm{GmbH}$, Germany), and the movement activity was converted to a voltage output which was digitized and integrated into 1-s bins. These conditioned signals (EEGs and gross body movements) were subjected to analog-to-digital conversion with 16-bit precision at a sampling rate of $128 \mathrm{~Hz}$ (NI PCI-6033E; National Instruments, Austin, TX). The digitized EEG waveform and integrated values for body movement were stored as binary computer files until subsequent analysis.

Postacquisition determination of vigilance state was done by visual scoring of 12-s epochs using custom software (ICELUS, M. R. Opp) written in LabView for Windows (National Instruments). The animal's behavior was classified as either SWS, rapid eye movement sleep (REMS), or waking based on previously defined criteria [26]. Briefly, SWS is characterized by large-amplitude EEG slow waves, high power density values in the delta frequency band $(0.5-4.0$ $\mathrm{Hz}$ ) and lack of gross body movements. During REMS, the amplitude of the EEG is reduced, the predominant EEG power density occurs within the theta frequency $(6.0-9.0$ $\mathrm{Hz}$ ) and there are phasic body twitches. During waking, the rats are generally active. There are protracted body movements. The amplitude of the EEG is similar to that observed during REMS, but power density values in the delta frequency band are generally greater than those in theta frequency band.

\section{Experimental Protocol}

The total of 35 Wistar rats were used in the postacquisition analysis and divided into 5 groups for this study. A 24-h undisturbed baseline EEG was recorded before initiating experiments in all groups. Rats in group $1(n=7)$ received PFS and $1 \%$ ethanol 20 minutes prior to the beginning of the light (rest) period at the $1^{\text {st }}$ and $2^{\text {nd }}$ experimental days, respectively, and CBD $0.5 \mu \mathrm{g}$ and $1.0 \mu \mathrm{g}$ were randomly injected at the subsequent $3^{\text {rd }}$ and $4^{\text {th }}$ days. Rats which received a high dose on the $3^{\text {rd }}$ day were given a low dose at the $4^{\text {th }}$ day, and vice versa. The same protocol was employed after a two-day break in the same group of rats, except the injection was given at 20 minutes before the dark onset. Rats in group $2(n=7)$ were used to clarify the involvement of presynaptic $5-\mathrm{HT}_{1 \mathrm{~A}}$ receptors by injections of buspirone $(0.5,2.0$ or 4.0 $\mu \mathrm{g})$ with $1.0 \mu \mathrm{g}$ CBD 20 minutes prior to the light period. Seven rats in group 3 were administered ritanserin (5.0 or $10.0 \mu \mathrm{g}$ ) with $1.0 \mu \mathrm{g}$ CBD 20 minutes prior to the light period to elucidate the effect of postsynaptic 5- $\mathrm{HT}_{2}$ receptors on CBD-induced sleep alteration. Rats in group $4(\mathrm{n}=8)$ were administered with 5-HT at doses of 3.0 and $10.0 \mu \mathrm{g}$ to determine whether increase 5-HT concentration in the CeA exhibits the similar sleep alteration as that of CBD. These animals also received $4.0 \mu \mathrm{g}$ buspirone or $10.0 \mu \mathrm{g}$ ritanserin alone at 20 minutes before the light onset to demonstrate the effects of buspirone and ritanserin per se on sleep-wake activity during the light period. Rats in group $5(\mathrm{n}=6)$ had a

similar protocol as those in group 2, except that those rats were received 100.0 or 300 pmol of ACEA with $1.0 \mu \mathrm{g} \mathrm{CBD}$ and were subsequently administered with $100.0 \mathrm{ng}$ AM-251 alone. Rats in group 5 also received 300 pmol ACEA administration as a positive control and $10 \%$ ethanol as a vehicle control after a two-day break. Sleep-wake activities were recorded at either the beginning of the light or the dark period after the injections and lasted for 24 hours.

\section{Statistical Analyses}

All values were presented as the mean \pm SEM for the indicated sample sizes. Two-way (manipulation $\mathrm{x}$ time) re-

A.
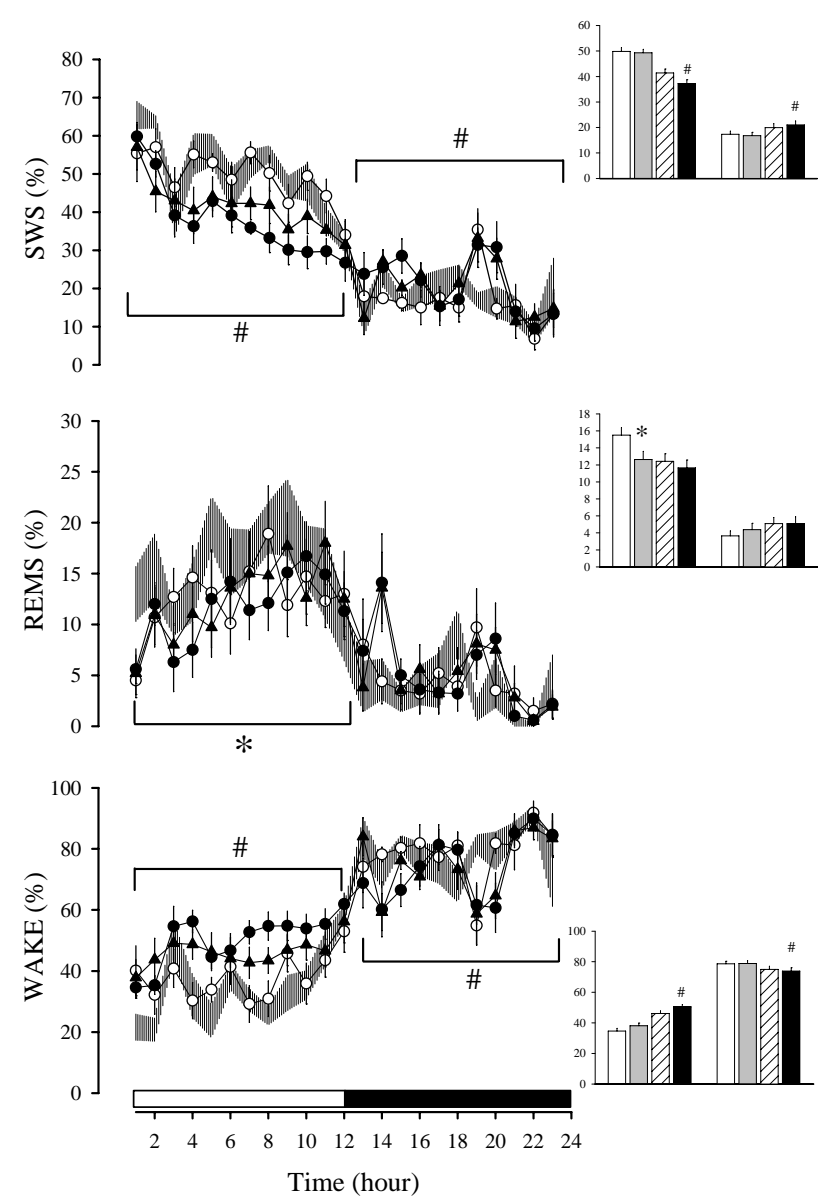

Fig. (2). The sleep-wake alteration induced by administration of CBD into CeA. A. Left panel: shaded area, open circles, closed triangles and closed circles represent the values obtained after injections of PFS, $1 \%$ ethanol, $0.5 \mu \mathrm{g}$ CBD and $1.0 \mu \mathrm{g}$ CBD, respectively. The dark and open portions of horizontal bars represent the dark and light periods of the 12:12h light:dark cycle. WAKE, wakefulness; REMS, rapid eye-movement sleep; SWS, slow wave sleep. B. Right panel: the summary bar graph of each vigilance state. Left four bars represent the data acquired during the light period after administrations of PFS, $1 \%$ ethanol, $0.5 \mu \mathrm{g} \mathrm{CBD}$ and $1.0 \mu \mathrm{g} \mathrm{CBD}$, respectively, and the other four bars depict the values obtained in the subsequent 12-h time block (the dark period). * represents statistically significant difference between the values obtained from PFS and $1 \%$ ethanol. \# denotes the statistically significant difference between the values obtained from $1 \%$ ethanol and those from CBD. 
peated measures analyses of variance (ANOVA) for the duration of each vigilance state (SWS, REMS, WAKE) and for sleep architecture parameters were performed, comparing before and after manipulation within subjects, across the two 12-h time blocks. The comparison of latency of different vigilance states between manipulations has been done by one-way ANOVA. An $\alpha$ level of $p \leq 0.05$ was taken as indicating a statistically significant difference.

\section{RESULTS}

\section{Effects of CBD on Sleep-Wake Activity}

All vigilance states (SWS, REMS, WAKE) were not altered after administering PFS when compared with the data acquired from the undisturbed baseline recordings (data not shown), which is consistent with our previous observation [26]. Since CBD was dissolved in $1 \%$ ethanol, we determined the sleep-wake alteration after administering $2 \mu \mathrm{l}$ of 1 $\%$ ethanol directly into the left CeA. Administration of $1 \%$ ethanol 20 minutes prior to the beginning of the light period did not alter SWS during the 12-h light period when compared with those data acquired after administration of PFS. The total time spent in SWS after injection of PFS and 1\% ethanol was $49.8 \pm 1.5 \%$ and $49.3 \pm 1.4 \%$ respectively (Fig. 2). REMS, however, decreased from $15.5 \pm 0.9 \%$ obtained after PFS administration to $12.6 \pm 1.0 \%$ after given $1 \%$ ethanol $\left(\mathrm{n}=7\right.$; manipulation $F_{(1,6)}=5.62, \mathrm{p}=0.037$; time $F_{(11,66)}=3.32, \mathrm{p}=0.117$; Fig. 2). The effects of ethanol on REMS may vary depending on the concentrations of ethanol, since there was no significant change of REMS when $10 \%$ ethanol (the vehicle for ACEA) was administered into the rats in group 5. The percentages of REMS after administra- tion of PFS and $10 \%$ ethanol were $17.6 \pm 1.0 \%$ and $19.9 \pm$ $1.1 \%$ (manipulation $F_{(1,6)}=3.60, \mathrm{p}=0.106$; time $F_{(11,66)}=$ $4.60, \mathrm{p}=0.076$ ), respectively. Microinjections of 0.5 and 1.0 $\mu \mathrm{g}$ CBD dose-dependently decreased SWS during the light period; the amounts of time spent in SWS during the light period were $41.4 \pm 1.5 \%$ (manipulation $F_{(1,6)}=5.43, \mathrm{p}=$ 0.059 ; time $F_{(11,66)}=3.34, \mathrm{p}=0.118$; when compared with the data obtained after $1 \%$ ethanol) and $37.9 \pm 1.5 \%$ (manipulation $F_{(1,6)}=26.35, \mathrm{p}=0.002$; time $F_{(11,66)}=6.87, \mathrm{p}=$ 0.04 ; when compared with the data obtained after $1 \%$ ethanol), respectively (Fig. 2). REMS during the light period was not altered by CBD. There was a mirror effect of wakefulness enhancement after CBD administration (Fig. 2). SWS during the subsequent $11-\mathrm{h}$ dark period was significantly enhanced when $1.0 \mu \mathrm{g} \mathrm{CBD}$ was administered prior to the beginning of the light period (manipulation $F_{(1,6)}=6.30, \mathrm{p}=$ 0.046 ; time $F_{(10,60)}=3.77, \mathrm{p}=0.10$; when compared with the data obtained after $1 \%$ ethanol; Fig. 2). The enhancement of SWS during the subsequent dark period might be a compensatory effect due to the sleep debt in the previous light period, because our results demonstrated that CBD has no statistically significant effect on any aspect of sleep during the dark period when it was injected into CeA before the dark onset. The percentages of time spent in SWS and REMS during the 12-h dark period after administration of $1 \%$ ethanol were $16.5 \pm 1.3 \%$ and $4.2 \pm 0.7 \%$, and those obtained after injection of $1.0 \mu \mathrm{g} \mathrm{CBD}$ were $18.9 \pm 1.4 \%$ (manipulation $F_{(1,6)}=2.59, \mathrm{p}=0.159 ;$ time $\left.F_{(11,66)}=2.42, \mathrm{p}=0.171\right)$ and $4.9 \pm 0.7 \%$ (manipulation $F_{(1,6)}=0.24, \mathrm{p}=0.644$; time $\left.F_{(11,66)}=1.86, \mathrm{p}=0.222\right)$.

Although the amount of REMS after receiving $1 \%$ ethanol was decreased, analysis of sleep-architecture parameters

Table 1. Effects of CBD, Buspirone, Ritanserin, ACEA and AM-251 on Sleep-Wake Architecture Parameters of Rats

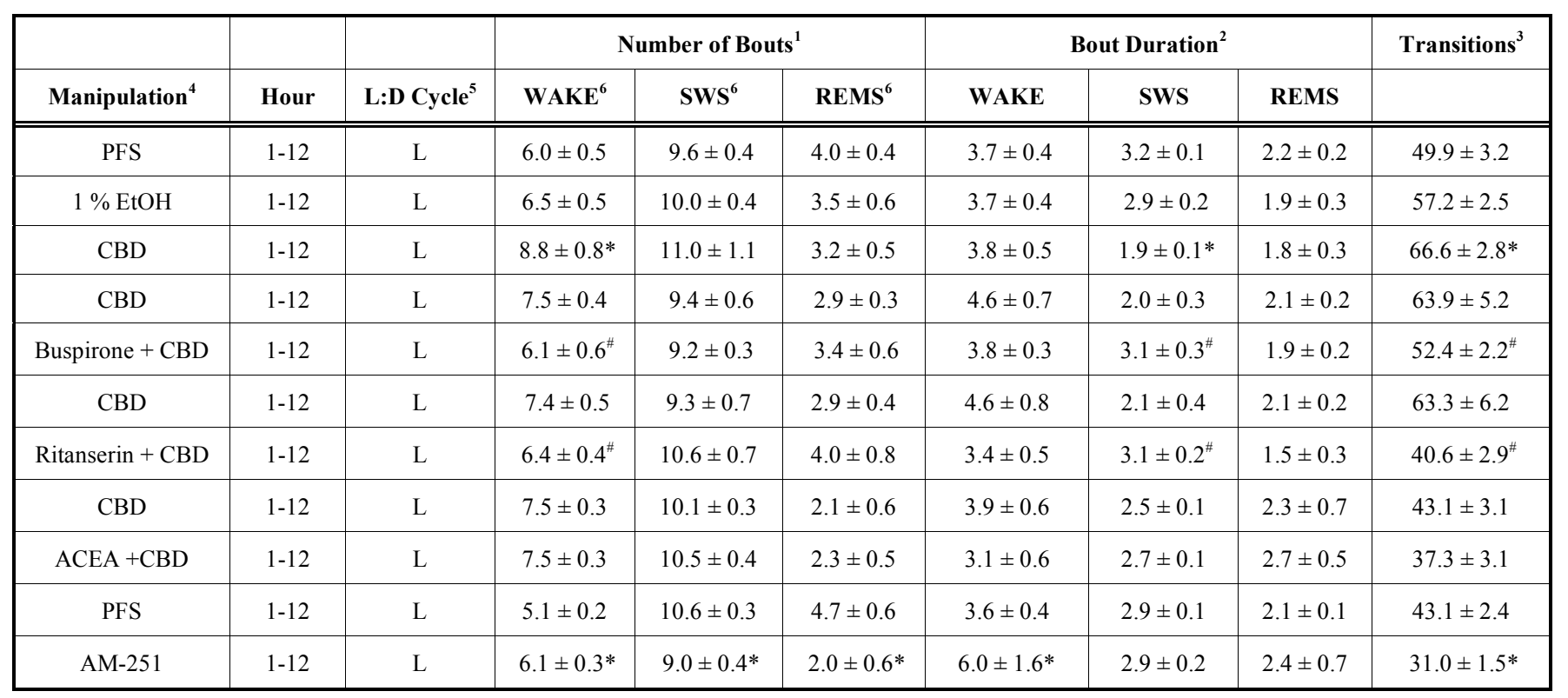

Values are Means \pm S.E.M. * denotes a statistically significant difference $(p<0.05)$ between values obtained after administration of vehicle (pyrogen-free saline [PFS] or $1 \%$ ethanol $[\mathrm{EtOH}])$ and those obtained after receiving substances. \# depicts a statistically significant difference $(p<0.05)$ between values obtained after CBD administration and those obtained after substance + CBD administration.

${ }^{1}$ Number of bouts per hour (mean \pm SEM) for each vigilance state.

${ }^{2}$ Mean ( \pm SEM) bout duration ( $\left.\mathrm{min}\right)$ for each vigilance state.

${ }^{3}$ Number of transitions from one behavioral state to another (mean \pm SEM) per hour.

${ }^{4}$ Experimental manipulation: $\mathrm{PFS}=$ pyrogen-free saline (vehicle); $\mathrm{EtOH}=$ ethanol (vehicle).

${ }^{5}$ Period of the light:dark cycle immediately prior to which injections were given: $\mathrm{L}=$ light period.

${ }^{6}$ Vigilance states: WAKE, wakefulness; SWS, slow-wave sleep; REMS, rapid eye movements sleep. 
across hours 1 to 12 revealed that both the number of REMS bouts and the REMS bout duration were not significantly altered (Table 1). The reduction in SWS and increase of wakefulness during the light period induced by CBD was primarily due to a decrease in SWS bout duration and an enhancement in the number of wakefulness bouts when compared to those parameters obtained after injection of $1 \%$ ethanol (Table 1). The number of transition from one state of vigilance to another during the 12-h light period increased significantly after CBD administration, indicative of sleep fragmentation (Table 1). EEG slow wave activities (SWAs) during SWS were not altered; SWAs during SWS in the 12-h light period were $912.4 \pm 0.5$ and $912.2 \pm 0.5 \mu \mathrm{V}^{2} / \mathrm{Hz}$ obtained after $1 \%$ ethanol and $1.0 \mu \mathrm{g}$ CBD, respectively. Administration of $1 \%$ ethanol or $1.0 \mu \mathrm{g}$ CBD did not significantly alter the latencies for entering the states of SWS and REMS from the beginning of the light period. The SWS latencies after administrations of PFS, $1 \%$ ethanol and $1.0 \mu \mathrm{g}$ CBD were $1.9 \pm 1.4,13.5 \pm 6.1(\mathrm{n}=7, \mathrm{p}=0.185$ when compared to PFS, one-way ANOVA) and $5.3 \pm 3.8$ minutes ( $\mathrm{p}=$ 0.860 when compared to PFS, one-way ANOVA), and the REMS latencies were $23.7 \pm 10.9,49.1 \pm 11.2(\mathrm{p}=0.324$ when compared to PFS, one-way ANOVA) and 40.5 \pm 12.6 minutes $(\mathrm{p}=0.599$ when compared to PFS, one-way ANOVA), respectively.

\section{The Involvement of Serotonergic Neurons in CBD- Induced Sleep Alteration}

Administrations of 5- $\mathrm{HT}_{1 \mathrm{~A}}$ receptor agonist, buspirone, dose-dependently blocked CBD-induced SWS decrease. The total amount spent in SWS acquired after double injections of $0.5,2.0$ or $4.0 \mu \mathrm{g}$ buspirone with CBD increased from $37.4 \pm 3.2 \%$ obtained after receiving $1.0 \mu \mathrm{g} \mathrm{CBD}$ to $40.2 \pm$ $1.6 \%$ (manipulation $F_{(1,6)}=0.53, \mathrm{p}=0.494$; time $F_{(11,66)}=$ $5.27, \mathrm{p}=0.061), 43.0 \pm 1.6 \%$ (manipulation $F_{(1,6)}=2.10, \mathrm{p}$ $=0.198$; time $\left.F_{(11,66)}=5.28, \mathrm{p}=0.061\right)$ or $49.2 \pm 1.5 \%$ (manipulation $F_{(1,6)}=17.72, \mathrm{p}=0.006$; time $F_{(11,66)}=7.52, \mathrm{p}=$ 0.034 ), respectively (Fig. 3). The CBD-induced suppressive effect in REMS is due to the non-specific effect of $1 \%$ ethanol vehicle as previous described. Buspirone exhibited no further effect on REMS in this group of rats (Fig. 3). Furthermore, our results have demonstrated that single administration of a high dose of buspirone $(4.0 \mu \mathrm{g})$ prior to the beginning of the light period did not significantly alter both SWS and REMS during the light period (Fig. 5A). Administration of ritanserin also dose-dependently blocked CBD's effect on SWS during the light period. The percentages of time spent in SWS increased from $37.5 \pm 1.5 \%$ after receiving $\mathrm{CBD}$ to $47.9 \pm 1.7 \%$ (manipulation $F_{(1,6)}=8.00, \mathrm{p}=$ 0.030 ; time $\left.F_{(11,66)}=3.42, \mathrm{p}=0.114\right)$ and $51.6 \pm 1.5 \%$ (manipulation $F_{(1,6)}=12.04, \mathrm{p}=0.013$; time $F_{(11,66)}=4.59, \mathrm{p}=$ 0.076 ) obtained after $5.0 \mu \mathrm{g}$ ritanserin $+\mathrm{CBD}$ and $10.0 \mu \mathrm{g}$ ritanserin $+\mathrm{CBD}$, respectively (Fig. 4). Ritanserin also exhibited no further effect on REMS in this group of rats (Fig. 4). A high dose of ritanserin, $10.0 \mu \mathrm{g}$, administered before the beginning of the light period did not significantly alter both SWS and REMS ( $\mathrm{n}=7$, Fig. 5A). Furthermore, administration of serotonin at doses of 3.0 and $10.0 \mu \mathrm{g}$ prior to the beginning of the light period significantly suppressed SWS, which is similar to the effect of CBD on SWS. The total amounts of time spent in SWS were decreased from $49.2 \pm$ $1.2 \%$ after receiving PFS injection to $41.8 \pm 1.4 \%$ (manipu-

lation $F_{(1,6)}=6.29, \mathrm{p}=0.046$; time $\left.F_{(11,66)}=2.37, \mathrm{p}=0.174\right)$ and $41.2 \pm 1.3 \%$ (manipulation $F_{(1,7)}=8.54, \mathrm{p}=0.022$; time $\left.F_{(11,77)}=3.50, \mathrm{p}=0.103\right)$ obtained after 3.0 and $10.0 \mu \mathrm{g}$ serotonin administrations, respectively (Fig. 5B). In addition, serotonin also reduced REMS during the light period, which is not exhibited by CBD administration. The percentages of REMS decreased from $18.6 \pm 0.9 \%$ after receiving PFS injection to $13.7 \pm 0.9 \%$ (manipulation $F_{(1,6)}=7.77, \mathrm{p}=0.032$; time $F_{(11,66)}=7.73, \mathrm{p}=0.032$ ) and $13.5 \pm 0.9 \%$ (manipulation $F_{(1,7)}=10.10, \mathrm{p}=0.016$; time $\left.F_{(11,77)}=7.75, \mathrm{p}=0.027\right)$ obtained after 3.0 and $10.0 \mu \mathrm{g}$ serotonin administrations, respectively (Fig. 5B).

A.
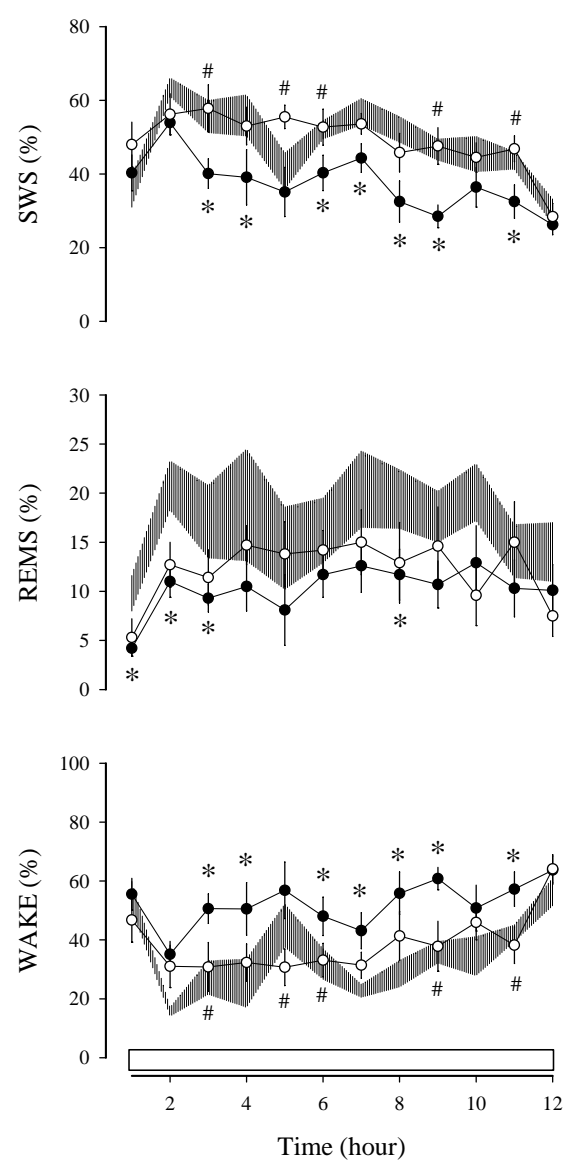

Fig. (3). Effects of presynaptic 5-HT $\mathrm{H}_{1 \mathrm{~A}}$ receptor agonist, buspirone on CBD-induced sleep alteration. A. Left panel: shaded area, closed circles and open circles represent the values obtained after injections of PFS, $1.0 \mu \mathrm{g} \mathrm{CBD}$ and $4.0 \mu \mathrm{g}$ buspirone $+1.0 \mu \mathrm{g} \mathrm{CBD}$, respectively, during the light period. B. Right panel: the summary bar graph of each vigilance state. The bars from left to right represent the data acquired during the 12-h light period after administrations of PFS, $1.0 \mu \mathrm{g}$ CBD, $0.5 \mu \mathrm{g}$ buspirone $+1.0 \mu \mathrm{g}$ CBD, $2.0 \mu \mathrm{g}$ buspirone $+1.0 \mu \mathrm{g}$ CBD and $4.0 \mu \mathrm{g}$ buspirone $+1.0 \mu \mathrm{g}$ CBD, respectively. * represents statistically significant difference between the values obtained from PFS and CBD. \# denotes the statistically significant difference between the values obtained from buspirone+CBD and those from CBD. 
A.
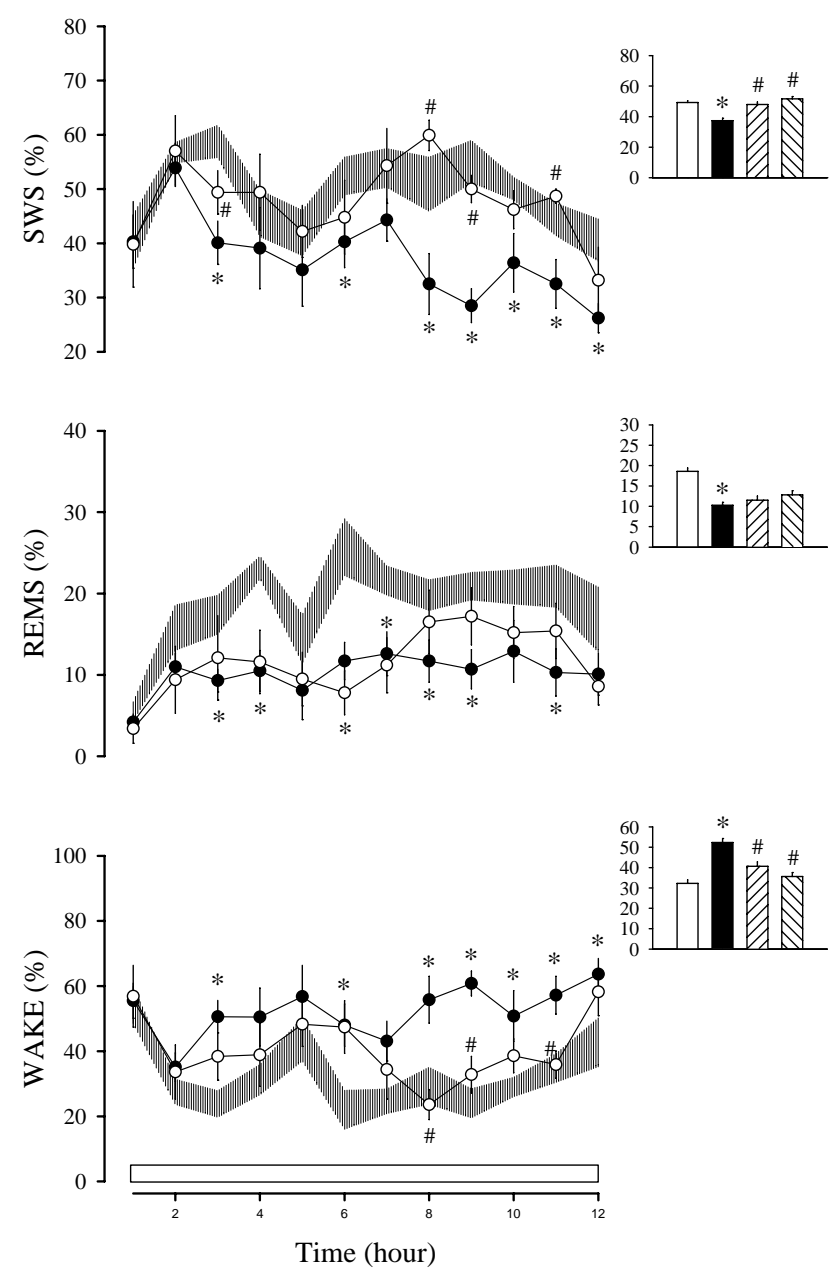

Fig. (4). Effects of postsynaptic 5-HT 2 receptor antagonist, ritanserin on CBD-induced sleep alteration. A. Left panel: shaded area, closed circles and open circles represent the values obtained after injections of PFS, $1.0 \mu \mathrm{g} \mathrm{CBD}$ and $10.0 \mu \mathrm{g}$ ritanserin $+1.0 \mu \mathrm{g} \mathrm{CBD}$, respectively, during the light period. B. Right panel: the summary bar graph of each vigilance state. The bars from left to right represent the data acquired during the 12-h light period after administrations of PFS, $1.0 \mu \mathrm{g} \mathrm{CBD}, 5.0 \mu \mathrm{g}$ ritanserin $+1.0 \mu \mathrm{g}$ CBD and 10.0 $\mu \mathrm{g}$ ritanserin $+1.0 \mu \mathrm{g} \mathrm{CBD}$, respectively. * represents statistically significant difference between the values obtained from PFS and CBD. \# denotes the statistically significant difference between the values obtained from ritanserin $+\mathrm{CBD}$ and those from $\mathrm{CBD}$.

The blockade of CBD-induced decrease in SWS and increase in wakefulness by buspirone was primarily due to an increase in SWS bout duration and a decrease in number of wakefulness bouts (Table 1). This observation indicates that buspirone reverses CBD-induced alteration of sleeparchitecture parameters during the light period. In addition, buspirone $+\mathrm{CBD}$ significantly decreased the number of tran- sitions when comparing to that obtained after CBD, suggesting that buspirone improves CBD-induced sleep fragmentation (Table 1). Application of ritanserin has similar effect as that of buspirone on reversing CBD-induced alteration in sleep-architecture parameters (Table 1).

\section{The Effects of $\mathrm{CB}_{1}$ Receptor Agonist (ACEA) and An- tagonist (AM-251)}

Administration of 300 pmol ACEA alone into the CeA exhibited no significant effect on all vigilance states during the 12-h light period when compared with the data acquired after administration of $10 \%$ ethanol (the vehicle). The amounts of time spent in SWS obtained after administrations of $10 \%$ ethanol and ACEA were $50.3 \pm 1.8 \%$ and $51.6 \pm$ $2.3 \%$, respectively (manipulation $F_{(1,5)}=4.275, \mathrm{p}=0.094$; time $\left.F_{(11,55)}=3.615, \mathrm{p}=0.116\right)$. The amounts of REMS were $20.6 \pm 2.0 \%$ and $18.9 \pm 1.1 \%$ obtained after $10 \%$ ethanol and ACEA, respectively (manipulation $F_{(1,5)}=3.226, \mathrm{p}=$ 0.132 ; time $\left.F_{(11,55)}=5.491, \mathrm{p}=0.066\right)$. Microinjections of $\mathrm{CB}_{1}$ agonist ACEA into the CeA partially and dosedependently reversed the CBD-induced SWS decrease during the light period, although it did not reach statistical significance during the 12-h time block. Administration of 300 pmol ACEA increased the total amount of time spent in SWS during the light period from $42.9 \pm 1.5 \%$ obtained after administration of $1.0 \mu \mathrm{g}$ CBD to $48.0 \pm 1.7 \%$ (manipulation $F_{(1,5)}=2.83, \mathrm{p}=0.168$; time $F_{(11,55)}=1.44, \mathrm{p}=0.297$; Fig. 6). However, ACEA did significantly block CBDinduced SWS decrease at several time points, such as hours 5, 8 and 11 (Fig. 6). Our result also demonstrated that microadministration of $\mathrm{CB}_{1}$ receptor antagonist AM-251, $100.0 \mathrm{ng}$ exhibits a similar effect as that of CBD on sleep-wake activity, except its efficacy is less than CBD's. AM-251 reduced SWS and enhanced wakefulness, but did not alter REMS. The percentages of SWS obtained after administering PFS (vehicle for AM-251), $1 \%$ ethanol (vehicle for CBD), CBD and AM-251 were $52.7 \pm 1.5 \%, 51.6 \pm 1.7 \%, 42.9 \pm 1.5 \%$ (manipulation $F_{(1,5)}=18.78, \mathrm{p}=0.007$; time $F_{(11,55)}=1.16, \mathrm{p}$ $=0.330$; when compared with data obtained from $1 \%$ ethanol) and $45.1 \pm 2.8 \%$ (manipulation $F_{(1,5)}=9.22, \mathrm{p}=0.029$; time $F_{(11,55)}=2.32, \mathrm{p}=0.189$; when compared with data obtained from PFS); the amounts of REMS were $18.9 \pm 1.5 \%$, $13.2 \pm 1.2 \%, 12.2 \pm 1.3 \%$ and $11.2 \pm 3.6 \%$, respectively.

Analysis of sleep-architecture parameters across hours 112 during the light period revealed that ACEA+CBD did not alter any aspect of sleep-wake architecture parameters when comparing with those obtained after CBD administration (Table 1), although ACEA partially blocked CBD-induced SWS decrease. Although AM-251 has a similar effect on SWS as CBD does, the alteration in sleep architecture is different. The reduction in SWS and enhancement of wakefulness induced by AM-251 were primarily due to the reduction in SWS bout's numbers and the increases of both the wakefulness bout's numbers and duration. The transition from one state of vigilance to another was decreased, which differs from the effect of CBD (Table 1).

\section{DISCUSSION}

The amygdala appears to be a critical brain structure which involves in the emotional, behavioral, and physiological responses associated with fear and anxiety [27-29]. In addition, the role of amygdala on arousal and sleep regula- 
A.

(a)
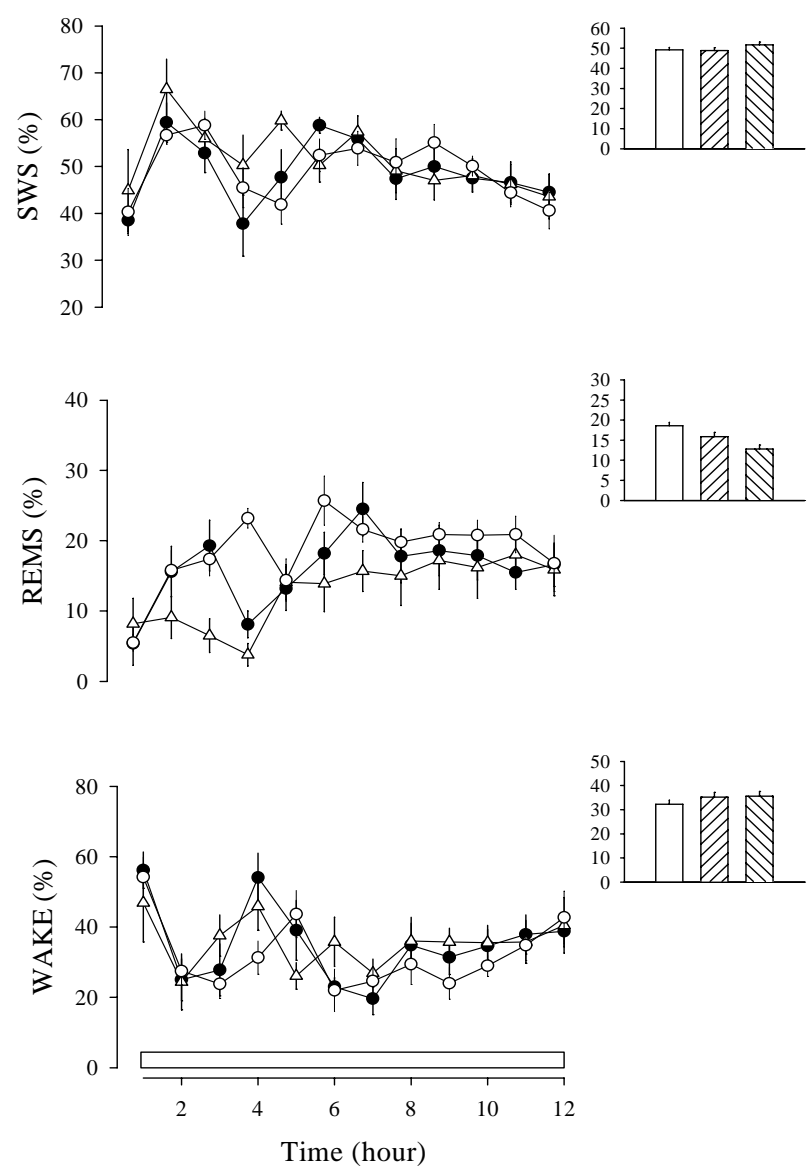

(b)

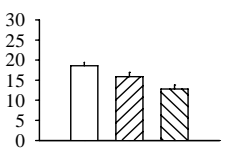

B.
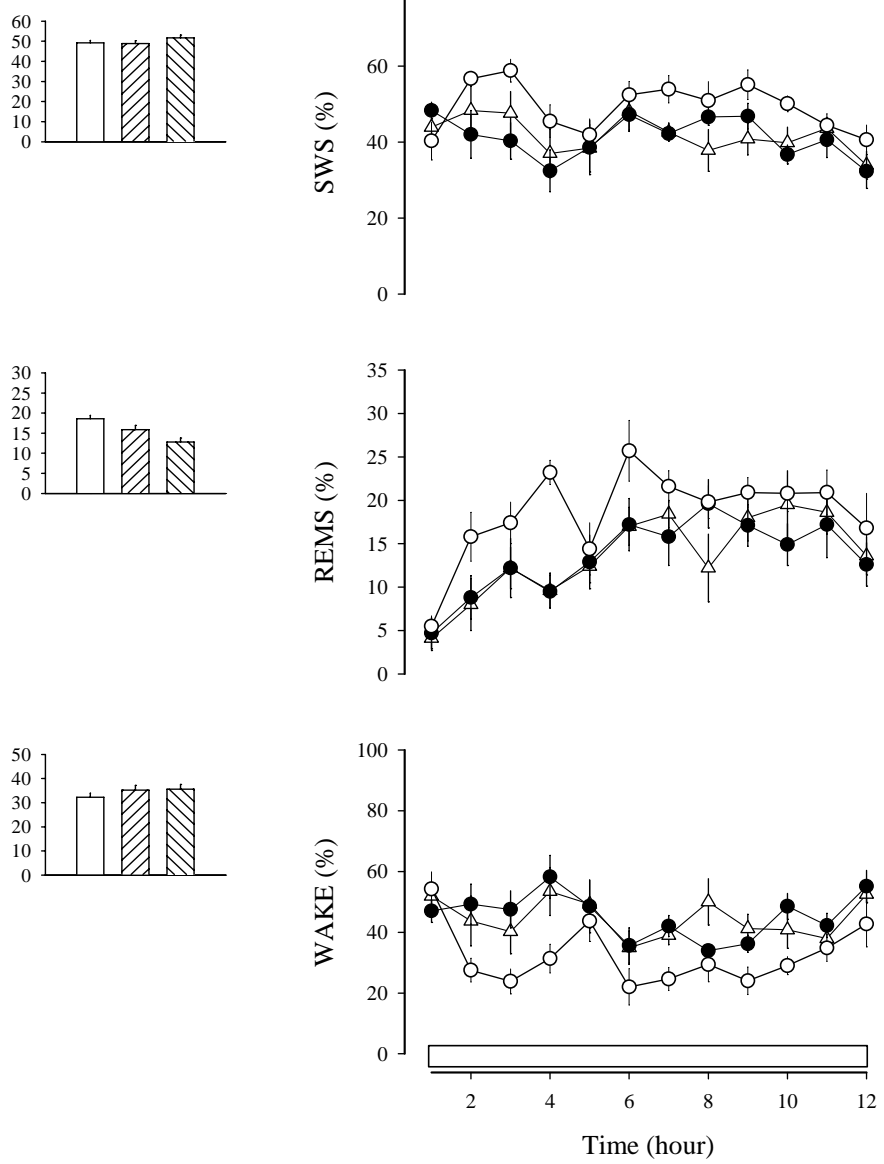
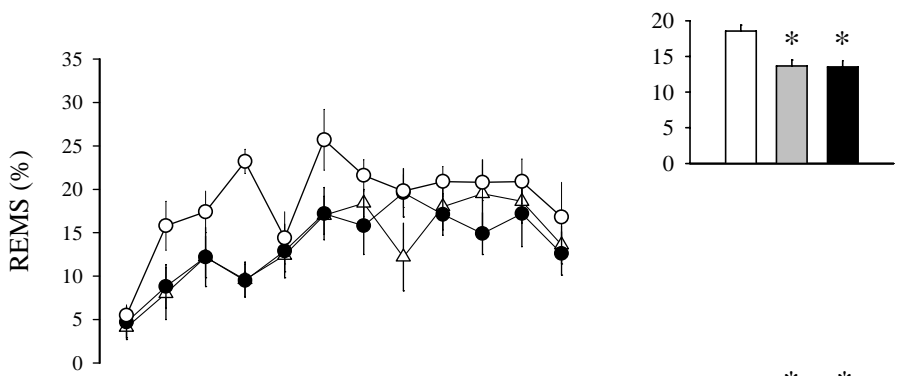

(b)
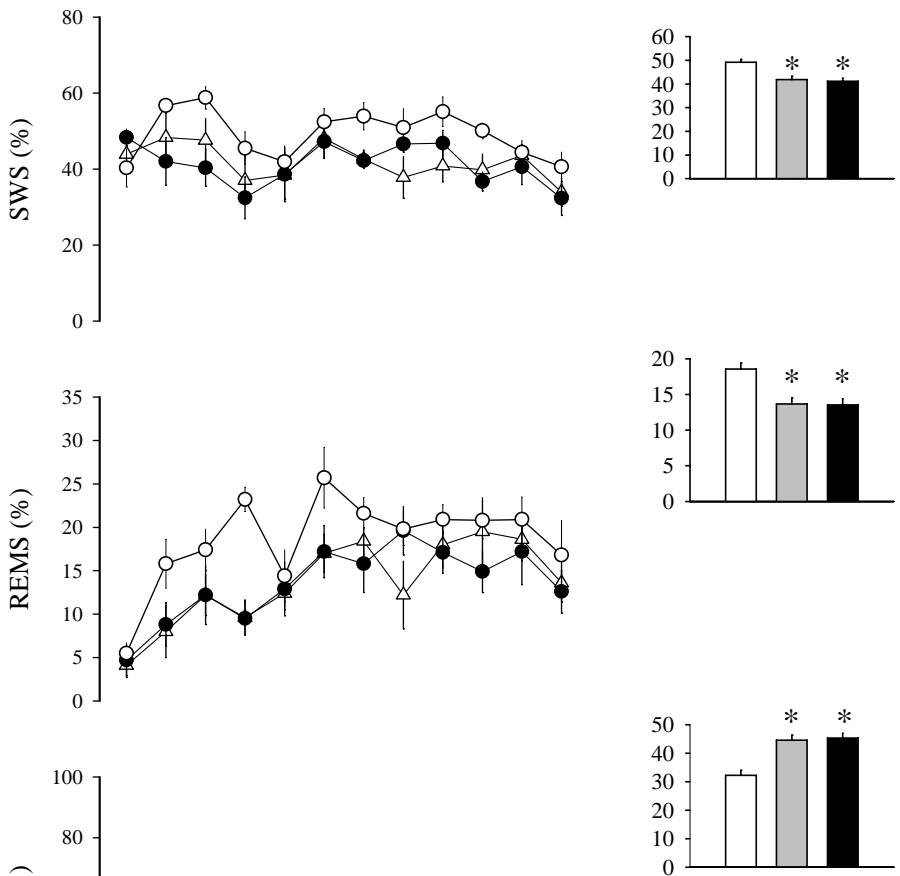

Fig. (5). A: The effects of buspirone and ritanserin on spontaneous sleep during the light period. (a). Left panel: open circles, closed circles and open triangles represent the values obtained after injections of PFS, $4.0 \mu \mathrm{g}$ buspirone and $10.0 \mu \mathrm{g}$ ritanserin, respectively, during the light period. (b). Right panel: the summary bar graph of each vigilance state. The bars from left to right represent the data acquired during the 12-h light period after administrations of PFS, $4.0 \mu \mathrm{g}$ buspirone and $10.0 \mu \mathrm{g}$ ritanserin, respectively. B: Sleep alteration induced by serotonin. (a). Left panel: open circles, open triangles and close circles represent the values obtained after injections of PFS, $3.0 \mu \mathrm{g}$ serotonin and $10.0 \mu \mathrm{g}$ serotonin, respectively, during the light period. (b). Right panel: the summary bar graph of each vigilance state. The bars from left to right represent the data acquired during the 12-h light period after administrations of PFS, $3.0 \mu \mathrm{g}$ serotonin and $10.0 \mu \mathrm{g}$ serotonin, respectively. * represents statistically significant difference between the values obtained from PFS and serotonin.

tion has also been emphasized [12,30,31]. Electrical stimulation of CeA suppresses delta wave activity in the frontal cortex and increases neocortical arousal [30]. Tang et al. have demonstrated that inactivating $\mathrm{CeA}$ neurons with tetrodotoxin (TTX), a sodium channel blocker, decreases REMS and increases SWS [31]. Administration of $\mathrm{GABA}_{\mathrm{A}}$ receptor agonist, muscimol, into the CeA suppresses REMS, but has no effect on SWS [12]. Lesion of amygdala produces more sleep and high proportion of REMS in rhesus monkeys [32]. Furthermore, neurons in the CeA send their outputs to various target structures, including the ventral tegmental area, locus coeruleus, lateral dorsal tegmental nucleus and basal forebrain, which are implicated in the behavioral and EEG arousal, the increased vigilance and the augmented attention [28]. As for the input innervations, it has been demonstrated that the rat's amygdala receives highly dense projections of serotonergic fibers from the dorsal raphe nucleus $[33,34]$. Moreover, sub-nuclei of macaque amygdala, such as the central nucleus, nucleus of the lateral olfactory tract, paralami- nar nucleus and anterior amygdaloid area, are densely innervated by serotonergic fibers [16]. Serotonergic receptors, especially the $5-\mathrm{HT}_{1}$ and $5-\mathrm{HT}_{2}$ receptors, are widely distributed throughout the amygdala $[35,36]$. The serotonergic system has been implicated in the mechanisms of fear and anxiety. For example, the selective serotonin uptake inhibitor (SSRI) is one of the efficacious medications in treating anxiety [37]. The genetic variation of the 5-HT transporter is correlated with the anxious behavior in humans and primates $[38,39]$. In addition to participate in fear and anxiety, serotonin has been widely proposed as a waking promoter. Evidence has demonstrated that systemic administration of 5$\mathrm{HT}_{1 \mathrm{~A}}$ receptor selective agonist increases wakefulness and sleep latency, and reduces REMS [40]. Blockade of 5- $\mathrm{HT}_{2 \mathrm{~A}}$ receptors results in an increase of NREMS in the $5-\mathrm{HT}_{2 \mathrm{~A}}+/+$ (wild-type) mice, but not in the $5-\mathrm{HT}_{2 \mathrm{~A}}-/-$ (knock-out) mice [41]. The discharging rate of major cells in the $\mathrm{CeA}$ is higher during wakefulness and REMS rather than during SWS [42]. Microinjection of 5-HT antagonist into the amygdala in- 
A.

B.
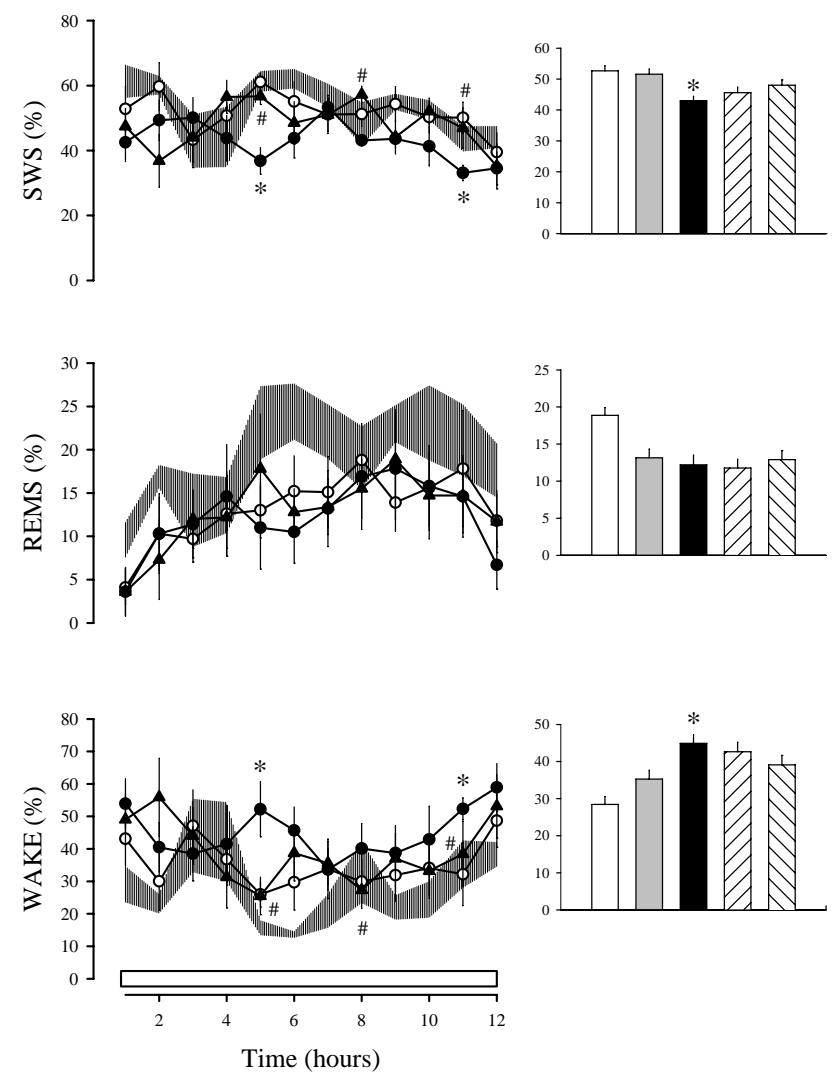

Fig. (6). The effects of $\mathrm{CB} 1$ receptor agonist, ACEA on CBDinduced sleep alteration. A. Left panel: shaded area, open circles, closed circles and closed triangles represent the values obtained after injections of PFS, ethanol, 1.0 $\mu \mathrm{g} \mathrm{CBD}$ and $300 \mathrm{pmol}$ ACEA $+1.0 \mu \mathrm{g}$ CBD, respectively, during the light period. B. Right panel: the summary bar graph of each vigilance state. The bars from left to right represent the data acquired during the 12-h light period after administrations of PFS, ethanol, $1.0 \mu \mathrm{g}$ CBD, 100 pmol ACEA+1.0 $\mu \mathrm{g} \mathrm{CBD}$ and 300 pmol ACEA+1.0 $\mu \mathrm{g} \mathrm{CBD}$, respectively. ${ }^{*}$ represents statistically significant difference between the values obtained from ethanol vehicle and CBD. \# denotes the statistically significant difference between the values obtained from $\mathrm{ACEA}+\mathrm{CBD}$ and those from $\mathrm{CBD}$.

creases sleep efficiency and ponto-geniculo-occipital (PGO) wave frequency in wakefulness and SWS [13]. Aforementioned observations suggest the involvement of amygdaloid serotonin in the sleep-waking regulation.

Our current observations are the first to demonstrate the sleep-wake alteration induced by a direct administration of $\mathrm{CBD}$ into the $\mathrm{CeA}$ and to elucidate its possible underlying mechanisms. CBD is the first compound isolated from the cannabis plant and it exhibits a broad pharmacological profile, including anti-convulsion, sedation, anti-anxiety, hypnotic effect, anti-psychosis and anti-inflammation [11].
Those pharmacological properties are more predominant in the therapeutic purposes rather than other active compounds, such as THC, because it is non-psychoactive [5]. Currently a cannabis extract, Sativex ${ }^{\circledR}$, which comprises THC and CBD in a ratio of $1: 1$, is used clinically. It has been reported that Sativex ${ }^{\circledR}$ dramatically improves subjective sleep parameters in patients with a variety of pain [43]. Orally taking CBDpredominant extract causes a mild activation effect, whereas taking THC results in a slight residual sedation [43]. Monti has indicated that intraperitoneal injections of CBD in a high and a low doses into rats exhibit an opposite effect on SWS latency [21]. Furthermore, ICV administration of CBD increases waking and decreases REMS in rats during the light period [22]. However, the underlying mechanism of CBD on sleep-wake activity remains unclear. Our result elicited that no any aspect of sleep-wake parameters during the dark period was altered when $\mathrm{CBD}$ was directly administered in to the $\mathrm{CeA}$ prior to the dark onset. However CBD produced a dose-dependent decrease of SWS during the light period when CBD was injected prior to the beginning of the light period. Our results also demonstrated that REMS was suppressed by $1 \%$ ethanol (the vehicle for CBD), but not altered by $10 \%$ ethanol (the vehicle for ACEA), suggesting that the effect of ethanol on sleep-wake activity may vary depending on the concentrations of ethanol. This observation is consistent with a previous result depicted by Ghosh et al. (1991) that ethanol inhalation decreases REMS at a lower dose, but exhibits no sleep alteration while a high concentration was given [44]. We then determined whether the CBD-induced sleep alteration is mediated by the activation of serotonergic system in the CeA, as we described previously that the CeA receives highly dense serotonergic projections from the raphe nucleus [33,34]. Evidence of a microdialysis study in which ICV administration of CBD into a rat increases the serotonin concentration in the nucleus accumbens at hours 1 and 2 after injection directs the possibility of serotonergic involvement [22]. Buspirone, which exhibits the anxiolytic effect through agonizing the presynaptic $5-\mathrm{HT}_{1 \mathrm{~A}}$ receptors [45], was the first substance to elucidate the involvement of serotonin in the CBD-induced sleep alteration. Our result has shown that buspirone blocked CBD-induced SWS alteration in a dose-dependent manner, suggesting the CBD's effect on sleep alteration may be mediated by increasing serotonin activation/release from the presynaptic terminals of 5-HT fibers (Fig. 7). This hypothesis is further confirmed by the blockade of CBD-induced SWS alteration by ritanserin, the post-synaptic 5- $\mathrm{HT}_{2}$ receptor antagonist [14]. In addition to the alteration of total amounts of sleep, analyses of sleeparchitecture parameters elicited that both buspirone and ritanserin exhibit the same direction to block the reduction of SWS bout's duration and the enhancement of waking bout's numbers produced after CBD administration. Administration of serotonin into the CeA mimicked CBD-induced SWS reduction, but it also reduced REMS. The amygdaloid serotonin has been implicated in REMS regulation in addition to the SWS. For example, REM-ON neurons recorded from the $\mathrm{CeA}$ were inhibited when stimulation of neurons in the dorsal raphe nucleus [42]. In addition, it has been reported that increasing activity of neurons in the locus coeruleus and raphe nucleus suppresses the activity of cholinergic pedunclopontine REM sleep effector cells [46]. Nevertheless, CBD has no further effect on REMS during the light period, which 


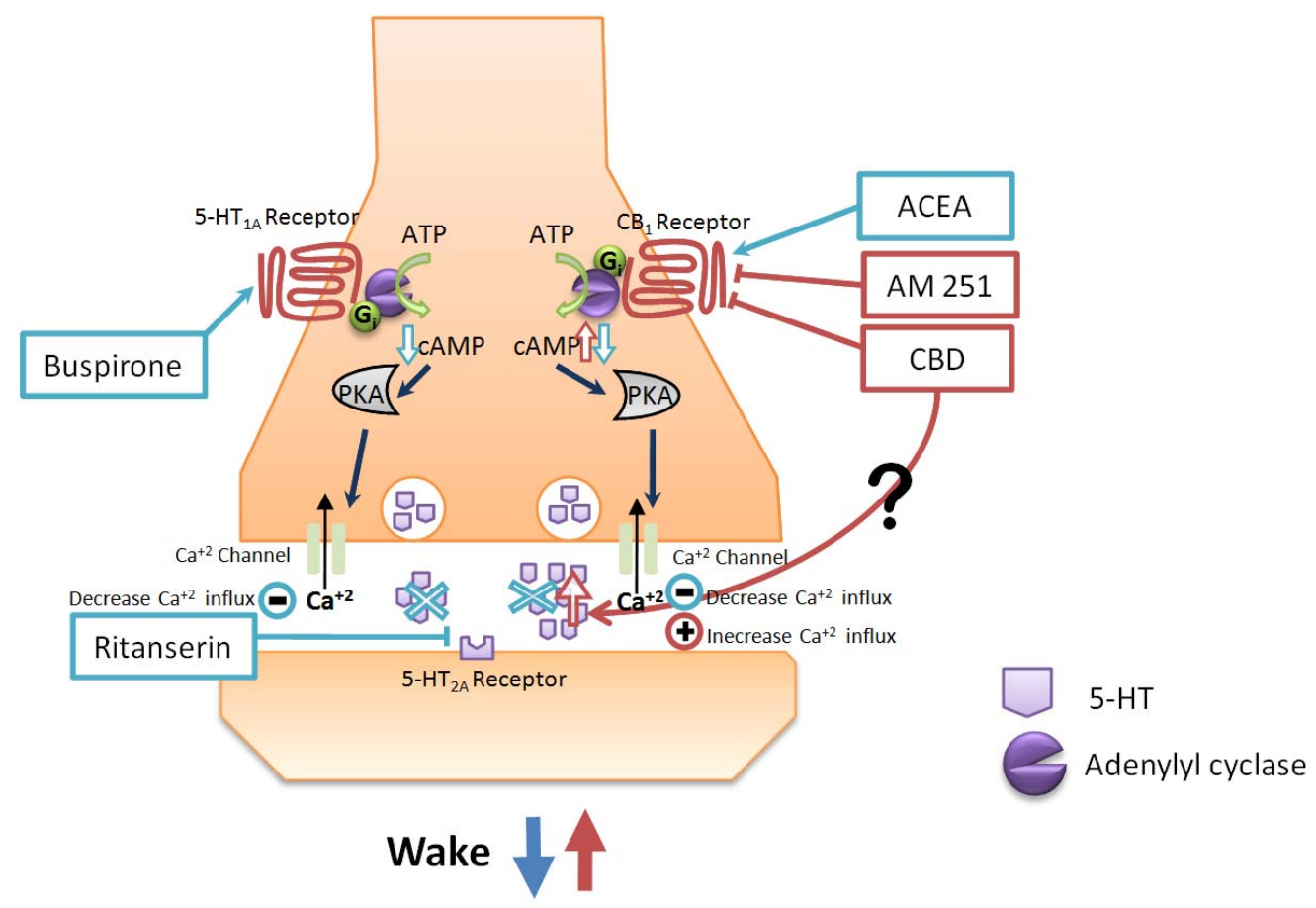

Fig. (7). The scheme of CBD's mechanism. CBD-induced SWS decrease is partially mediated by antagonizing presynaptic $\mathrm{CB}_{1}$ receptors at the serotonergic terminals, which results in the cAMP enhancement, and subsequently enhancing serotonin release from axon terminals. Additionally, there is an unidentified mechanism (indicated as “?”) which may also contribute to the CBD's action. “上” indicates the antagonizing action; " $\leftarrow$ " depicts the agonizing effect; blue color indicates the pathway for decreasing wakefulness; red color represents the pathway for increasing waking. PKA: protein kinase A.

might be due to that ethanol (vehicle) masks CBD's effect and/or CBD is less effective to activate the serotonergic system in amygdala than an exogenous 5-HT injection does.

The function of endocannabinoid system has been demonstrated that the endocannabinoid produced from postsynaptic neurons serves as a retrograde signaling and binds to $\mathrm{CB}_{1}$ receptors on presynaptic terminals to inhibit neurotransmitter release $[4,17]$. The presynaptic $\mathrm{CB}_{1}$ receptors located on axon terminals are highly expressed in the basal ganglia, cerebellum, hippocampus and olfactory cortex, and are moderately expressed in the cerebral cortex, amygdala, septum and brain stem [6-8]. Evidence suggests that cannabinoid $\mathrm{CB}_{1}$ receptors and 5-HT transporters are colocalized in the amygdala [18], implying that activation of presynaptic cannabinoid $\mathrm{CB}_{1}$ receptors might reduce 5-HT release from axon terminals. It has been further demonstrated that $\Delta^{9}$-THC-induced catalepsy-like immobilization is mediated by decreased 5-HT neurotransmission in the nucleus accumbens [47], and that $\mathrm{CB}_{1}$ receptor protein exists on serotonergic fibers and synapses expressing the 5-HT uptake transporter in both the hippocampus and amygdala [48]. A1though evidence suggests that CBD has a low binding affinity to the $C_{1}$ receptors $[5,11]$, it has recently been emphasized that $\mathrm{CBD}$ displays a high potency on antagonizing $\mathrm{CB}_{1}$ receptors in the mouse vas deferens [23] and in mouse brain [24]. They found that CBD antagonizes both CP 55940induced and R-(+)-WIN 55212-mediated stimulations of $\left[{ }^{35} \mathrm{~S}\right] \mathrm{GTP} \gamma \mathrm{S}$ binding to the mouse brain, which demonstrates the similar effects of $\mathrm{CB}_{1}$ receptor antagonists, rimonabant and O-2654 [24]. The $\mathrm{K}_{\mathrm{B}}$ value of $\mathrm{CBD}$ for antagonizing $\mathrm{CP}$ 55940 -induced stimulation of $\left[{ }^{35} \mathrm{~S}\right] \mathrm{GTP} \gamma \mathrm{S}$ binding to the mouse brain was below its corresponding $\mathrm{CB}_{1} \mathrm{~K}_{\mathrm{i}}$ value [24]. Both CP 55940 and R-(+)-WIN 55212 are the cannabinoid receptor agonists. We further elucidated the involvement of presynaptic $\mathrm{CB}_{1}$ receptors by employing a $\mathrm{CB}_{1}$ agonist ACEA, and found that ACEA partially and dose-dependently reversed the $\mathrm{CBD}$-induced SWS decrease during the light period. Furthermore, a $\mathrm{CB}_{1}$ specific antagonist, AM-251, produced a similar reduction in SWS during the light period, although the effect of AM-251 was less effective than that of CBD. Analyses of sleep-wake architecture parameters revealed that AM-251 increased the bout duration of wakefulness and decreased the numbers of SWS and REMS bouts in addition to the increase of waking bout's numbers that was also produced by CBD. However, CBD-induced decrease of SWS bout's duration was not observed by AM-251. The observation implicates that antagonizing presynaptic $\mathrm{CB}_{1}$ receptor on serotonergic fibers only partially explain the actions of $\mathrm{CBD}$ on sleep alteration, additional mechanism(s) may involve in its sleep regulation. In fact, it has been proposed that the effects of CBD at anti-convulsion, antianxiety, anti-psychosis, anti-nausea and anti-rheumatoid arthritic properties might be because of the inhibition of endogenous endocannabinoid (anandamide) uptake and hydrolysis or the anti-oxidative effect $[11,49]$. If the inhibition of anandamide hydrolysis is involved in CBD-induced sleep alteration, the increased anandamide would decrease 5-HT release via an agonistic action of presynaptic $\mathrm{CB}_{1}$ receptors, which may result in an increase of SWS. However, this conjectural outcome conflicts with our current observation of SWS decrease caused by CBD. Nervertheless, investigating further possible mechanism(s) that contributes to the CBD's 
sleep regulation is worthwhile, since the underlying mechanisms of $\mathrm{CBD}$ are complicated and remain ambiguous. In addition, the amygdaloid CBD-induced sleep alteration is unexpected and paradoxical. In clinical, sleep disruption is commonly found in patients with anxiety, such as the generalized anxiety disorder, panic disorder, and posttraumatic stress disorder [50]. Conversely, sleep deprivation exacerbates the relapse of anxiety condition [50]. Anxiogenic agents mostly produce arousal activation and anxiolytics conversely reduce arousal. Nevertheless, few anxiolytics exhibit the CBD-like paradoxical effect of arousal stimulatation. For instance, nicotine increases the inhibition of sleeppromoting systems facilitated by noradrenaline [51], and enhances discharge rate of dorsal raphe 5-HT neurons during REMS [52]. Another example is that neuropeptide S exerts both anxiolytic and arousal effects in rodents [53]. Our results demonstrated that CBD exerts an unique pharmacological property to promote the wakefulness in addition to its well-known anxiolytic effect. Furthermore, it also suggests that two distinct mechanisms may dominate the different actions of $\mathrm{CBD}$, the anti-anxiety and sleep-wake regulation. Interfering hypothalamic neuropeptides, such as corticotropin-releaseing hormone $(\mathrm{CRH})$ that is well known to involve in the stress response, may play a role in CBD's anxiolytic properties. However, the anxiolytic mechanism of CBD and its role of sleep-wake regulation in an anxious rat need to be further investigated.

\section{CONCLUSION}

In conclusion, our current results demonstrated the sleep regulation of amygdaloid $\mathrm{CBD}$ as the scheme depicting in Fig. (7). $\mathrm{CBD}$ antagonizes $\mathrm{CB}_{1}$ receptors at the pre-synaptic terminals of serotonergic fibers in the $\mathrm{CeA}$, enhances the release of serotonin, and subsequently binds to the postsynaptic $5-\mathrm{HT}_{2}$ receptors to reduce SWS and increase wakefulness. Serotonin and $\mathrm{CB}_{1}$ receptor antagonist AM-251 could produce a similar effect as that $\mathrm{CBD}$ does, and the CBD-induced SWS reduction was blocked by $\mathrm{CB}_{1}$ agonist, presynaptic 5-HT $\mathrm{HA}_{1 \mathrm{~A}}$ agonist and post-synaptic 5- $\mathrm{HT}_{2}$ antagonist. These results elicit the possible mechanism of CBD on sleep-wake regulation and provide a therapeutic direction for CBD in treating somnolence.

\section{DISCLOSURE/CONFLICT OF INTEREST}

This is not an industry supported study. Authors have indicated no financial conflicts of interest.

\section{ACKNOWLEDGEMENTS}

This work was supported by National Science Council grant NSC96-2628-B-002-029-MY3. We thank Mr. Brian Chang for English revising and Mr. Yi-Fong Tsai's technical assistance in this project.

\section{REFERENCES}

[1] ElSohly M. In: Grotenhermen F, Russo E, Eds. Cannabis and cannabinoids. Pharmacology, toxicology, and therapeutic potential. Binghamton/New York, Haworth Press 2002; 27-36.

[2] Mechoulam R. Marihuana chemistry. Science 1970; 168: 11591166.

[3] Mechoulam R, Shani A, Edery H, Grunfeld Y. Chemical basis of hashish activity. Science 1970; 169: 611-612.

[4] Chevaleyre V, Takahashi KA, Castillo PE. Endocannabinoidmediated synaptic plasticity in the CNS. Annu Rev Neurosci 2006; 29: 37-76.
[5] Grotenhermen F. Cannabinoids and the endocannabinoid system. Cannabinoids 2006; 1: 10-14.

[6] Freund TF, Katona I, Piomelli D. Role of endogenous cannabinoids in synaptic signaling. Physiol Rev 2003; 83: 1017-1066.

[7] Herkenham M, Lynn AB, Little MD, et al. Cannabinoid receptor localization in brain. Proc Natl Acad Sci USA 1990; 87: 19321936.

[8] Tsou K, Brown S, Sanudo-Pena MC, Mackie K, Walker JM. Immunohistochemical distribution of cannabinoid $\mathrm{CB} 1$ receptors in the rat central nervous system. Neuroscience 1998; 83: 393-411.

[9] Galiegue S, Mary S, Marchand J, et al. Expression of central and peripheral cannabinoid receptors in human immune tissues and leukocyte subpopulations. Eur J Biochem 1995; 232: 54-61.

[10] Buckley NE, Burbridge D, Buranapramest M, Ferguson T, Paau RY. Experimental methods to study the role of the peripheral cannabinoid receptor in immune function. Methods Mol Med 2006; 123: 19-40.

[11] Mechoulam R, Parker LA, Ruth G. Cannabidiol: an overview of some pharmacological aspects. J Clin Pharmacol 2002; 42: 11S19S.

[12] Sanford LD, Parris B, Tang X. GABAergic regulation of the central nucleus of the amygdala: implications for sleep control. Brain Res 2002; 956: 276-284.

[13] Sanford LD, Tejani-Butt SM, Ross RJ, Morrison AR. Amygdaloid control of alerting and behavioral arousal in rats: involvement of serotonergic mechanisms. Arch Ital Biol 1995; 134: 81-99.

[14] Graeff FG, Netto CF, Zangrossi H Jr. The elevated T-maze as an experimental model of anxiety. Neurosci Biobehav Rev 1998; 23: 237-246.

[15] Groenink L, Joordens RJ, Hijzen TH, Dirks A, Olivier B. Infusion of flesinoxan into the amygdala blocks the fear-potentiated startle. Neuroreport 2000; 11: 2285-2288.

[16] Bauman MD, Amaral DG. The distribution of serotonergic fibers in the macaque monkey amygdala: an immunohistochemical study using antisera to 5-hydroxytryptamine. Neuroscience 2005; 136: 193 203.

[17] Schlicker E, Kathmann M. Modulation of transmitter release via presynaptic cannabinoid receptors. Trends Pharmacol Sci 2001; 22: 565-572.

[18] Ashton JC, Darlington CL, Smith PF. Co-distribution of the cannabinoid $\mathrm{CB}_{1}$ receptor and the 5-HT transporter in the rat amygdale. Eur J Pharmacol 2006; 537: 70-71.

[19] Feinberg I, Jones R, Walker JM, Cavness C, Floyd T. Effects of marijuana extract and tetrahydrocannabinol on electroencephalographic sleep patterns. Clin Pharmacol Ther 1976; 19: 782-794.

[20] Feinberg I, Jones R, Walker JM, Cavness C, March J. Effects of high dosage $\Delta$-9-tetrahydrocannabinol on sleep patterns in men. Clin Pharmacol Ther 1975; 17: 458-466.

[21] Monti JM. Hypnoticlike effects of cannabidiol in the rat. Psychopharmacology 1977; 55: 263-265.

[22] Murillo-Rodriguez E, Millan-Aldaco D, Palomero-Rivero M, Mechoulam R, Drucker-Colin R. Cannabidiol, a constituent of Cannabis sativa, modulates sleep in rats. FEBS Lett 2006; 580: 4337-4345.

[23] Pertwee RG, Ross RA, Craib SJ, Thomas A. (-)-cannabidiol antagonizes cannabinoid receptor agonists and noradrenaline in mouse vas deferens. Eur J Pharmacol 2002; 456: 99-106.

[24] Thomas A, Baillie GL, Phillips AM, Razdan RK, Ross RA, Pertwee RG. Cannabidiol displays unexpectedly high potency as an antagonist of $\mathrm{CB}_{1}$ and $\mathrm{CB}_{2}$ receptor agonists in vitro. Br J Pharmacol 2007; 150: 613-623.

[25] Paxinos G, Waton C. Eds. The rat brain in stereotaxic coordinates $4^{\text {th }}$ ed. San Diego: Academic Press 1998.

[26] Chang FC, Opp MR. Blockade of corticotropin-releasing hormone $(\mathrm{CRH})$ receptors reduces spontaneous waking in the rat. Am J Physiol Regul Integr Comp Physiol 1998; 275: R793-R802.

[27] Davis M. The role of the amygdala in fear and anxiety. Annu Rev Neurosci 1992; 15: 353-375.

[28] Davis M, Whalen PJ. The amygdala: vigilance and emotion. Mol Psychiatry 2001; 6: 13-34.

[29] Kalin NH, Shelton SE, Davidson RJ. The role of the central nucleus of the amygdala in mediating fear and anxiety in the primate. J Neurosci 2004; 24: 5506-5515.

[30] Kapp BS, Supple WF Jr, Whalen PJ. Effects of electrical stimulation of the amygdaloid central nucleus on neocortical arousal in the rabbit. Behav Neurosci 1994; 108: 81-93. 
[31] Tang X, Yang L, Liu X, Sanford LD. Influence of tetrodotoxin inactivation of the central nucleus of the amygdala on sleep and arousal. Sleep 2005; 28: 923-930.

[32] Benca RM, Obermeyer WH, Shelton SE, Droster J, Kalin NH. Effects of amygdala lesions on sleep in rhesus monkeys. Brain Res 2000; 879: 130-138.

[33] Vertes RP. A PHA-L analysis of ascending projections of the dorsal raphe nucleus in the rat. J Comp Neurol 1991; 313: 643-668.

[34] Vertes RP, Fortin WJ, Crane AM. Projections of the median raphe nucleus in the rat. J Comp Neurol 1999; 407: 555-582.

[35] Pompeiano M, Palacios JM, Mengod G. Distribution of the serotonin 5-HT2 receptor family mRNAs: comparison between 5HT2A and 5-HT2C receptors. Brain Res Mol Brain Res 1994; 23 : 163-178.

[36] Stuart AM, Mitchell IJ, Slater P, Unwin HL, Crossman AR. A semi-quantitative atlas of 5-hydroxytryptamine-1 receptors in the primate brain. Neuroscience 1986; 18: 619-639.

[37] Mogg K, Baldwin DS, Brodrick P, Bradley BP. Effect of shortterm SSRI treatment on cognitive bias in generalized anxiety disorder. Psychopharmacology 2004; 176: 466-470.

[38] Heils A, Teufel A, Petri S, et al. Allelic variation of human serotonin transporter gene expression. J Neurochem 1996; 66: 26212624.

[39] Lesch KP, Meyer J, Glatz K, et al. The 5-HT transporter genelinked polymorphic region (5-HTTLPR) in evolutionary perspective: alternative biallelic variation in rhesus monkeys. J Neural Transm 1997; 104: 1259-1266.

[40] Monti JM, Jantos H. Effects of the 5-HT1A receptor ligands flesinoxan and WAY 100635 given systemically or microinjected into the laterodorsal tegmental nucleus on REM sleep in the rat. Behav Brain Res 2004; 151: 159-166.

[41] Popa D, Lena C, Fabre V, et al. Contribution of 5-HT2 receptor subtypes to sleep-wakefulness and respiratory control, and functional adaptations in knock-out mice lacking 5-HT2A receptors. J Neurosci 2005; 25: 11231-11238.
[42] Jha SK, Ross RJ, Morrison AR. Sleep-related neurons in the central nucleus of the amygdala of rats and their modulation by the dorsal raphe nucleus. Physiol Behav 2005; 86: 415-426.

[43] Russo EB, Guy GW, Robson PJ. Cannabis, pain, and sleep: lessons from therapeutic clinical trials of Sativex, a cannabis-based medicine. Chem Biodivers 2007; 4: 1729-1743.

[44] Ghosh TK, Copeland RL, Pradhan SN. Effects of ethanol inhalation on EEG in rats. Pharmacol Biochem Behav 1991; 38: 293-297.

[45] Tunnicliff G. Molecular basis of buspirone's anxiolytic action. Pharmacol Toxicol 1991; 69: 149-156.

[46] Mamelak M. A model for narcolepsy. Can J Psychol 1991; 45: 194-220

[47] Sano K, Mishima K, Koushi E, et al. Delta(9)-tetrahydrocannabinol-induced catalepsy-like immobilization is mediated by decreased 5-HT neurotransmission in the nucleus accumbens due to the action of glutamate-containing neurons. Neuroscience 2008; 151: 320-328.

[48] Haring M, Marsicano G, Lutz B, Monory K. Identification of the cannabinoid receptor type 1 in serotonergic cells of raphe nuclei in mice. Neuroscience 2007; 146: 1212-1219.

[49] Mechoulam R, Hanus L. Cannabidiol: an overview of some chemical and pharmacological aspects. Part I: chemical aspects. Chem Phys Lipids 2002; 121: 35-43.

[50] Mellman TA. Sleep and anxiety disorders. Psychiatr Clin North Am 2006; 29: 1047-1058.

[51] Saint-Mleux B, Eggermann E, Bisetti A, et al. Nicotinic enhancement of the noradrenergic inhibition of sleep-promoting neurons in the ventrolateral preoptic area. J Neurosci 2004; 24: 63-67.

[52] Guzman-Marin R, Alam MN, Mihailescu S, Szymusiak R, McGinty D, Drucker-Colin R. Subcutaneous administration of nicotine changes dorsal raphe serotonergic neurons discharge rate during REM sleep. Brain Res 2001; 888: 321-325.

[53] Okamura N, Reinscheid RK. Neuropeptide S: a novel modulator of stress and arousal. Stress 2007; 10: 221-226.

(C) Yi et al.; Licensee Bentham Open.

This is an open access article licensed under the terms of the Creative Commons Attribution Non-Commercial License (http://creativecommons.org/licenses/by-nc/3.0/) which permits unrestricted, non-commercial use, distribution and reproduction in any medium, provided the work is properly cited. 